\title{
A INTERVENÇÃO PSICOPEDAGÓGICA NA INDISCIPLINA ESCOLAR
}

\section{ARTIGO ORIGINAL}

SILVA, Romilson Alves da ${ }^{1}$

\section{SILVA, Romilson Alves da. A intervenção psicopedagógica na indisciplina} escolar. Revista Científica Multidisciplinar Núcleo do Conhecimento. Ano. 06, Ed. 12, Vol. 11, pp. 85-95. Dezembro de 2021. ISSN: 2448-0959, Link de acesso: https://www.nucleodoconhecimento.com.br/educacao/a-intervencao-

psicopedagogica, DOI: 10.32749/nucleodoconhecimento.com.br/educacao/aintervencao-psicopedagogica

\section{RESUMO}

A indisciplina na escola é um dos principais problemas enfrentados por profissionais que trabalham no contexto educacional das escolas públicas brasileiras na contemporaneidade, as consequências disso ocasionam dificuldades no processo de ensino e aprendizado. O objetivo deste trabalho é investigar a indisciplina sobre a ótica psicopedagógica, as causas e implicações dentro do educandário. Como questão norteadora, apresenta-se a seguinte indagação: qual o papel do psicopedagogo diante da indisciplina escolar? Utilizando da metodologia de revisão bibliográfica, foi possível concluir que a falta de disciplina nas escolas interfere não só na educação infantil, no ensino fundamental e no ensino médio de escolas públicas como também interfere nas escolas particulares, porém com menos frequência, além de compreender que o papel do profissional psicopedagogo educacional e clínico é de ajudar os profissionais da escola a sanar problemas que

\footnotetext{
${ }^{1}$ Mestrando em Ensino na área de Educação Profissional e Tecnológica (ProfEPT), pelo Instituto Federal do Amazonas (IFAM), Campus Manaus Centro (CMC), pós-graduado em nível de Especialização em Geografia, Meio Ambiente e Sustentabilidade, pela Faculdade Venda Nova do Imigrante (FAVENI); pós-graduado em nível de Especialização em Psicopedagogia Institucional e Clínica, pela Faculdade Venda Nova do Imigrante (FAVENI); pós-graduado em nível de Especialização em Pedagogia Escolar: Supervisão, Orientação e Administração, pela Faculdade Internacional de Curitiba (FACINTER)/Instituto Brasileiro de Pós-Graduação e Extensão (IBPEX); graduado em Geografia, pela Faculdade Educacional da Lapa (FAEL); graduado em Pedagogia, pela Universidade Estadual Vale do Acaraú (UVA).
}

RC: 104239

Disponível em: https://www.nucleodoconhecimento.com.br/educacao/a-intervencaopsicopedagogica 
dificultem o processo de ensino e aprendizagem por meio de estratégias metodológicas.

Palavras-chave: Indisciplina, Escola, Aprendizagem.

\section{INTRODUÇÃO}

$\mathrm{Na}$ atualidade, a educação brasileira passa por diversas transformações, não só no que se refere à estrutura curricular, mas também em relação à falta de disciplina, fazendo com que o papel do profissional psicopedagogo se destaque, auxiliando os professores com suas intervenções psicopedagógicas dentro das instituições de ensino, com o intuito de sanar essa problemática. A indisciplina tem representado um dos grandes entraves para que a aprendizagem se efetive nas escolas brasileiras. A família e os lócus onde as escolas estão inseridas também têm uma grande contribuição nessa relação interpessoal na comunidade escolar, gerando esses conflitos nas instituições.

Dessa forma, o trabalho do psicopedagogo nas instituições de ensino é de grande importância, já que ajuda na inserção de novas metodologias, planejamento e formas de ensino nas escolas, auxiliando para que os professores desenvolvam trabalhos de excelência nas escolas e consigam ensinar os alunos de modo que a aprendizagem seja eficaz.

Portilho (2003, p. 125), conceitua o estudo da psicopedagogia, do seguinte modo:

Psicopedagogia tem por objeto de estudo a aprendizagem do ser humano que na sua essência é social, emocional e cognitivo o ser cognoscente, um sujeito que para aprender pensa, sente e age em uma atmosfera, que ao mesmo tempo é objetiva e subjetiva, individual e coletiva, de sensações e de conhecimentos, de ser e vir a ser, de não saber e de saber. Essa ciência estuda o sujeito na sua singularidade, a partir do seu contexto social e de todas as redes relacionais a que ele consegue pertencer.

A psicopedagogia procura abarcar as nuances do que acontece na escola em relação ao processo de ensino e aprendizagem, as dificuldades que os educandos têm na compreensão e interpretação das atividades pedagógicas propostas pela 
escola. Mas considerando que a indisciplina é um dos principais complicadores que os profissionais da educação enfrentam nas escolas, o psicopedagogo, com suas intervenções, é o profissional que ajudará o professor a solucionar esses problemas, dentre outros.

Dessa maneira, os objetivos deste trabalho consistem em: investigar a indisciplina sobre a ótica psicopedagógica, as causas e implicações dentro do educandário a vencer essa problemática de falta de disciplina; analisar na literatura alguns fatores que colaboram para que os alunos se tornem indisciplinados nas escolas; compreender de que forma o psicopedagogo pode intervir mediante a indisciplina. Como questão norteadora, apresentam-se a seguinte indagação: qual o papel do psicopedagogo diante da indisciplina escolar?

A metodologia usada nesta pesquisa baseia-se na revisão bibliográfica, através da qual são pesquisados artigos, periódicos e outras publicações que abordem o assunto, a fim de embasar as discussões aqui propostas.

\section{A INDISCIPLINA NA ESCOLA}

Sabe-se que os profissionais da educação, principalmente os educadores, têm dificuldades na questão da indisciplina dos educandos nas escolas públicas municipais e estaduais no Brasil. O comportamento dos alunos da educação infantil, ensino fundamental e médio vem apresentando dificuldades na relação com os profissionais na escola. $O$ trabalho do especialista em psicopedagogia é essencial junto aos professores, já que facilita, com sua intervenção, esse processo de relacionamento por vezes conturbado. De acordo com Tiba (1996, p. 99), a disciplina é: "um conjunto de regras que devem ser obedecidas para êxito do aprendizado escolar. Portanto, ela é uma qualidade de relacionamento humano entre o corpo docente e os alunos em sala de aula".

Um dos principais desafios dos profissionais da educação nos dias de hoje é a indisciplina dos alunos nas escolas, dificultando o fazer pedagógico em sala de aula. 
As famílias, na sua grande maioria, ausentes, a pobreza, a falta de instrução, fazem com que os alunos na escola representem uma responsabilidade que vai além das questões pedagógicas para os professores e gestão escolar. Para Amado (1999, p. 25) "quando falamos de indisciplina, não falamos de um mesmo fenômeno, mas de uma diversidade de fenômenos por detrás de uma mesma significação".

A psicopedagogia focaliza na aprendizagem dos alunos, quando essa aprendizagem não acontece, os psicopedagogos, através de suas intervenções, auxiliam na solução da problemática em relação à aprendizagem dos alunos. A psicopedagogia é a área do conhecimento que estuda a aprendizagem dos alunos. Serafini et al. (2011, p. 51) definem a aprendizagem da seguinte maneira:

Aprendizagem é um processo que envolve vínculos individuais e coletivos que resultam das interações do sujeito com o meio, da ação do cuidador e das articulações entre o saber e o não saber. É um processo permeado, no caso do ser humano, por um clima e um tom socioafetivo, que produz instrumentos para mudar a si e ao mundo e vice-versa. É um movimento que envolve o mundo íntimo, a subjetividade, o desejo e, também, o contexto no qual se dá. É o processo de conhecer, o processo de vida que se dá por articulações possíveis e que amplia os domínios cognitivos para conexões cada vez mais complexas.

É necessário que todos os envolvidos no processo de ensino e aprendizagem interajam: os profissionais da educação, a família e psicopedagogo, para que esse processo ocorra na escola de forma satisfatória. Sendo assim, este trabalho está focado na questão da falta de disciplina, ou seja, a indisciplina e as intervenções propostas pelo profissional psicopedagogo.

Sabe-se que a indisciplina em sala de aula prejudica a prática pedagógica do professor, seus projetos e planejamentos em sala de aula, e compromete o processo de aprendizagem do próprio aluno. Na sua grande maioria, as famílias desses educandos não colaboram, ou não conseguem educar seus filhos em casa e dão muito trabalho com falta de um bom comportamento na escola. Os alunos precisam ter o referencial de que na escola acontece a sistematização do ensino, a compreensão da estrutura curricular e que é necessário que eles se tornem sujeitos independentes da sua informação.

RC: 104239

Disponível em: https://www.nucleodoconhecimento.com.br/educacao/a-intervencaopsicopedagogica 
A disciplina (...) significa a capacidade de comandar a si mesmo, de se impor aos caprichos individuais, às veleidades desordenadas, significa, enfim, uma regra de vida. Além disso, significa a consciência da necessidade livremente aceita, na medida em que é reconhecida como necessária para que um organismo social qualquer atinja o fim proposto. (FRANCO, 1986, p. 40).

Segundo Franco (1986, p. 25) "Só se alcança a disciplina através do trabalho do coletivo da escola, de uma escola onde o aluno se sinta feliz e corresponsável pelo êxito escolar". Os profissionais da escola e família têm que estar juntos para que os educandos possam ter vontade de estudar, respeitar os colegas e os profissionais da escola, e respeitar os colegas de sala de aula.

Conforme Makarenko (1977, p. 75).

Antes de tudo, nossa disciplina deve ser uma disciplina consciente. (...) Nossa disciplina, como fenômeno moral e político, deve vir acompanhada de consciência, isto é, de uma noção do que é disciplina e para que a necessitamos.

O aluno deve ser um dos principais atores na construção do seu conhecimento, e fazer com que a escola seja um tanto prazerosa em suas vidas e assim, consequentemente, terá uma educação de qualidade e será uma pessoa disciplinada na escola. O papel da escola é desenvolver habilidades e preparar o sujeito para a vida política, social e para o trabalho (MARQUES, 2001, p. 17).

Os profissionais da educação assumem, na maioria das vezes, o papel da família, embora a escola tenha como principal função, dentre outras, o estímulo dos alunos na aquisição dos conhecimentos sistematizados. Boa parte das escolas não contam em seu quadro com o especialista em psicopedagogia institucional e clínico, o que se observa são os profissionais efetivos lotados nesses espaços, sem nenhuma formação para o cargo, dificultando o trabalho dos professores nas escolas.

Observa-se que o trabalho do psicopedagogo tem que estar presente nas escolas públicas brasileiras, já que podem desenvolver intervenções junto ao trabalho dos professores nas escolas, viabilizando melhorias no trabalho desses professores que apresentam a indisciplina no contexto do diário de suas aulas. "O psicopedagogo 
deve atuar intervindo como mediador entre o sujeito e sua história traumática, ou seja, a história que lhe causou a dificuldade de aprender". (PORTO, 2005, p. 109).

A indisciplina ocorre devido ao fato de haver alunos que não têm apreço pelas aulas, por professores e profissionais da educação em geral, muitos não têm o hábito de estudar, as famílias, na sua grande maioria, não estimulam os filhos estudarem, já que boa parte dessas famílias é representada por analfabetos que não tiveram as mesmas oportunidades na educação. O psicopedagogo é o profissional que vai desenvolver estratégias, essas táticas de intervenção procuram desvendar o porquê de os alunos serem indisciplinados nas escolas.

O psicopedagogo tem que levar em conta o conhecimento tácito do educando, da mesma forma que todo profissional da educação, os alunos indisciplinados, em muitos casos, são pessoas que querem ter atenção, em muitos casos são filhos de pais separados, criados sem a presença dos pais, a falta da estrutura familiar, geralmente os de classe social menos favorecidas são os que têm mais problemas de indisciplina na escola. O psicopedagogo tem que agir juntamente com os professores em relação ao processo de ensino e aprendizagem, e atuar no progresso do processo de ensino e aprendizagem nas escolas. "O psicopedagogo necessita conhecer e valorizar as diferentes aprendizagens construídas ao longo da história de vida da pessoa, considerando que estas podem contribuir para enaltecer a aprendizagem". Blaszko et al. (2016, p. 146).

Sabe-se que existem escolas com falta de profissionais, como por exemplo a insuficiência no quadro docente. O profissional psicopedagogo, que para muitos não tem importância para escola, fica ainda mais relegado. Em alguns casos, professores sem formação específica exercem a função de forma inadequada. Além disso, há escolas em que o projeto político pedagógico está ultrapassado, fazendo com que os alunos não sejam estimulados nas atividades propostas pela escola, e quando frequentam só aparecem na escola sem interesse de fato no estudo, têm comportamento desarmonioso na escola, vão para a escola para evadir das aulas, amedrontar professores. 
A indisciplina tem revelado uma grande dificuldade que os professores enfrentam no cotidiano das escolas. Porém, em algumas escolas, o problema da indisciplina não se restringe a alguns alunos indisciplinados, na verdade a toda a turma é indisciplinada. Percebe-se que as mídias sociais, a violência na sociedade, a falta de uma família estruturada, contribuem com a dificuldade no processo de ensino e aprendizagem na escola.

Entre as primeiras vamos encontrar, por exemplo, a influência hoje exercida pelos meios de comunicação, a violência social e o ambiente familiar. As causas encontradas no interior da escola, por sua vez, incluem o ambiente escolar e as condições de ensino-aprendizagem, os modos de relacionamentos humanos, o perfil dos alunos e as capacidades de se adaptar aos esquemas da escola. (GARCIA, 1999, p. 104).

O cenário da educação brasileira na contemporaneidade precisa do trabalho dos profissionais psicopedagogos nas escolas, pois esse profissional é capaz de desenvolver metodologias juntamente com os trabalhadores em educação e a família, para que consigam de fato que a questão da indisciplina seja sanada nas escolas. A integração entre escola e família é importante para que o processo de ensino e aprendizado aconteça nessas instituições.

A indisciplina acontece em todos os níveis da educação básica, desde a educação infantil, ensino fundamental e ensino médio das escolas públicas. Nas escolas privadas, a questão da indisciplina acontece com menor frequência, devido às regras serem cobradas, os pais, por pagarem a escola e terem uma preocupação maior com o aprendizado dos filhos, os regimentos são seguidos por todos, de modo que o comprometimento e assiduidade seja maior pelo alunado.

O trabalho na instituição escolar apresenta duas naturezas: O primeiro diz respeito a uma psicopedagogia voltada para o grupo de alunos que apresentam dificuldades na escola. O seu objetivo é reintegrar e readaptar o aluno à situação de sala de aula, possibilitando o respeito às necessidades $e$ ritmos. Tendo como meta desenvolver as funções cognitivas integradas ao afetivo, desbloqueando e canalizando o aluno gradualmente para a aprendizagem dos conceitos conforme os objetivos da aprendizagem formal. O segundo tipo de trabalho refere-se à assessoria junto a pedagogos, orientadores e professores. Tem como objetivo trabalhar as questões pertinentes às relações vinculares professor-aluno e redefinir os 
procedimentos pedagógicos, integrando o afetivo e o cognitivo, através da aprendizagem dos conceitos $\mathrm{e}$ as diferentes áreas do conhecimento. (SANTOS, 2016, p. 02).

O trabalho do psicopedagogo na escola se dá juntamente com os professores em relação aos alunos que apresentam problemas de aprendizagem e falta de comportamento adequado na escola; as intervenções psicopedagógicas se dão no sentido de sanar esses problemas de ensino e aprendizagem e de falta de disciplina na escola. Dessa maneira, o trabalho do psicopedagogo se dá de forma preventiva, para que não ocorram problemas no ensino e aprendizagem na escola. Vejamos um dos principais objetivos da psicopedagogia. "É uma área de estudo que tem como objetivo a aprendizagem humana, que em sua natureza sistemática é ação social, cognitiva e emocional. (UJIIE, 2016, p. 13).

O psicopedagogo estimula os alunos na aquisição de conhecimento, incita os alunos na obtenção de um comportamento satisfatório na escola. Além disso, o profissional da psicopedagogia tem o papel de considerar e verificar o que atrapalha um ensino de qualidade na escola, somando forças juntos aos profissionais da educação e a família, por isso é importante que se desenvolvam políticas públicas que garantam que todas as escolas tenham em seu quadro o profissional da psicopedagogia.

Osti et al. (2005, p. 152), comentam que:

A psicopedagogia educacional objetiva que todos profissionais de educação, considerando diretores, professores e coordenadores pedagógicos repensem o papel da escola frente às dificuldades da criança e os vários fatores envolvidos numa situação de aprendizagem. Por outro lado, crianças com dificuldades de aprendizagem necessitam de atendimento específico, o que evidencia que em certos casos a escola não consegue resolver todos os problemas desta ordem sozinha, necessitando de ajuda de um profissional especializado.

O profissional da psicopedagogia terá que desenvolver suas intervenções pedagógicas de maneira que todos os profissionais da educação se envolvam para que os alunos aprendam, tenha um bom comportamento na escola. Por isso. psicopedagogo terá que ser mais valorizado dentro da instituição de ensino, para que possa fazer seus trabalhos com eficiência. 
A educação pública paraense e brasileira precisa ser reinventada, e a escola terá de fazer seu papel social, que seria de educar, e educar com qualidade que os cidadãos desse país necessitam e têm por direito estabelecido em leis vigentes. $O$ trabalho do psicopedagogo terá que apreciado por todos os profissionais da educação.

\section{CONSIDERAÇÕES FINAIS}

Conclui-se que a indisciplina é uma das maiores problemáticas que têm uma complexidade enorme e aflige os profissionais da educação brasileira. Os profissionais das escolas públicas são os que mais sofrem com a falta de disciplina (indisciplina) nessas instituições de ensino, os profissionais da educação particular, também são afligidos pela problemática da falta de disciplina, porém com menor ocorrência, ocorre tanto na educação infantil, no ensino fundamental, quanto ensino médio, geralmente das escolas públicas.

Dessa forma, o profissional psicopedagogo educacional e clínico surge de forma a ajudar os profissionais nas escolas, com suas intervenções e estratégias metodológicas nas atividades propostas das escolas, no sentido de sanar essas problemáticas que atrapalham o processo de ensino e aprendizagem.

Sabe-se que a desobediência é um acontecimento que está presente no cotidiano das escolas, os alunos têm dificuldades de aceitar, acatar ordens, dificultando o planejamento dos gestores, equipe técnica pedagógica, e professores. A família terá que ser envolvida nas atividades pedagógicas das escolas, junto com as intervenções propostas pelos psicopedagogos.

O profissional psicopedagogo é essencial nas escolas públicas, porém muitas não têm o trabalho deste profissional, é quando tem os mesmos encontram problemas nas escolas para desenvolverem seus trabalhos de maneira eficaz e eficiente, faltam recursos, materiais, falta formação continuada, há profissionais da educação que não gostam do trabalho do psicopedagogo, a família também rejeita, em alguns 
casos, esses profissionais. O papel do psicopedagogo é desafiador na educação do Brasil, é necessário esclarecimentos, formação e informação com a comunidade escolar e família sobre a importância desse profissional no processo de ensino e aprendizagem e na questão da indisciplina na escola, situação que tanto aflige os profissionais da educação na atualidade.

\section{REFERÊNCIAS}

AMADO, João da Silva. Indisciplina na aula: regras, tarefas e relação pedagógica. Psicologia, Educação e Cultura, Lisboa, v. 3, n. 1, p. 53-72, 1999.

BLASZKO, C. E. et al. Atuação psicopedagógica na equipe multidisciplinar: relevância da interação do psicopedagogo com os profissionais que atendem alunos com dificuldades específicas de aprendizagem. In: UJIIE, N. T. Psicopedagogia clínica e institucional: nuances, nexos e reflexos. Curitiba: CRV, 2016. p. 143-152.

FRANCO, L. A. C. A Indisciplina na Escola: Problemas de Educação Escolar. São Paulo: CENAFOR, 1986.

GARCIA. J. Indisciplina na Escola: uma reflexão sobre a dimensão preventiva. Rv. Paran. Desenvo., Curitiba, n. 95, jan., p. 101-108, 1999.

MAKARENKO, A. La colectividad y la Educación de la Personalidad. Moscou: Editorial Progresso, $1977 . \quad$ Disponível em: https://www.marxists.org/espanol/makarenko/la-colectividad-y-la-educacion-de-lapersonalidad.pdf. Acesso em: 30 ago. 2021.

MARQUES, R. Saber educar: guia do professor. Lisboa: Presença, 2001.

OSTI, A. et al. A atuação do Psicopedagogo em Instituições de Ensino: Relato de Experiência. Revista de Educação, Londrina, v.8, n. 8, p. 150 - 155, 2005. Disponível

em: 
$<$ http://www.pgsskroton.com.br/seer/index.php/educ/article/view/2229/2124>. Acesso em: 31 ago. 2020.

PORTILHO, E. M. L. Conhecer-se para conhecer. In: BARBOSA, L. M. S. Psicopedagogia um portal para inserção social. Petrópolis, RJ: Vozes, 2003. p. 125-131.

PORTO, O. Bases da Psicopedagogia: diagnóstico e intervenção nos problemas de aprendizagem. Rio de Janeiro: Wak, 2005. p.11-52.

SANTOS, R. A. O Psicopedagogo na instituição escolar: Intervenções psicopedagógicas no processo de ensino-aprendizagem. 2016. Disponível em: <http://www.psicopedagogiabrasil.com.br/artigos.htm>. Acesso em: 30 ago. 2020.

SERAFINI, A. Z. et al. A aprendizagem: várias perspectivas e um conceito. In: PORTILHO, E. M. L. Alfabetização aprendizagem e conhecimento na formação docente. Curitiba: Champagnat, 2011. p. 43-69.

TIBA, I. Disciplina, limite na medida certa. São Paulo: Gente, 1996.

UJIIE, N. T. Psicopedagogia, definição e enquadramento de área: nuances, pontos e contrapontos. In: UJIIE, N. T. Psicopedagogia Clínica e Institucional: nuances, nexos e reflexos. Curitiba: CRV, 2016. p. 13-22.

Enviado: Fevereiro, 2021.

Aprovado: Dezembro, 2021. 